\title{
THE EFFORT TEST IN ANGINA PECTORIS
}

\author{
BY \\ PAUL WOOD, M. McGREGOR, O. MAGIDSON, and W. WHITTAKER \\ From the Institute of Cardiology, National Heart Hospital \\ Received May 31, 1950
}

The diagnosis of angina pectoris is usually based on the history alone, and in most cases this is conclusive. When, however, the quality, site, distribution, duration, or relationship to effort of a suspicious chest pain does not conform to classical concepts, a reliable objective test is needed. Two such tests have been used widely, the effort test as developed by Master (1942) and the anoxic test of Levy (1941). In the hands of most investigators both these tests have given positive results in only about half of cases in which the diagnosis was clinically certain. As the inhalation of 10 per cent oxygen requires special apparatus, is time-consuming, relatively expensive, not without danger, and causes electrocardiographic changes that differ from the normal only in degree, and as trials by our colleagues were not encouraging, it seemed more profitable to concentrate on improving the effort test. Using a simple modification of Master's technique, one of us (P. W.) soon realized that diagnostic ischæmic curves could be obtained in about 90 per cent of patients with clinically certain angina pectoris in whom the resting electrocardiogram was normal. The object of this paper is to present an analysis of thèse results together with a larger series of cases similarly investigated at the Institute of Cardiology.

TABLE I

Cases presenting With Angina Pectoris

\begin{tabular}{|c|c|c|c|c|c|c|c|c|c|c|}
\hline \multirow[b]{2}{*}{ Clinical diagnosis } & & & \multicolumn{8}{|c|}{ Electrocardiogram at rest } \\
\hline & & - & No. & Normal & Ischæmic & $\begin{array}{c}\text { Old } \\
\text { Infarct }\end{array}$ & $\begin{array}{l}\text { Recent } \\
\text { Infarct }\end{array}$ & $\begin{array}{l}\text { Hyper- } \\
\text { tensive } \\
\text { pattern }\end{array}$ & $\begin{array}{c}\text { Left } \\
\text { B.B.Bl. }\end{array}$ & $\begin{array}{c}\text { Right } \\
\text { B.B.Bl. }\end{array}$ \\
\hline $\begin{array}{l}\text { Pure angina } \\
\text { Hypertensive angina } \quad . . \\
\text { Old cardiac infarct } \\
\text { Acute coronary insufficiency } \\
\text { Aortic stenosis .. }\end{array}$ & $\begin{array}{l}\cdots \\
\cdots \\
\cdots \\
\cdots\end{array}$ & $\begin{array}{l}\cdots \\
\cdots \\
\cdots \\
\cdots\end{array}$ & $\begin{array}{r}44 \\
21 \\
18 \\
14 \\
3\end{array}$ & $\begin{array}{r}31 \\
2 \\
3 \\
0 \\
0\end{array}$ & $\begin{array}{r}8 \\
6 \\
1 \\
14 \\
0\end{array}$ & $\begin{array}{r}2 \\
2 \\
14 \\
0 \\
0\end{array}$ & $\begin{array}{l}1 \\
1 \\
0 \\
0 \\
0\end{array}$ & $\begin{array}{r}0 \\
10 \\
0 \\
0 \\
3\end{array}$ & $\begin{array}{l}1 \\
0 \\
0 \\
0 \\
0\end{array}$ & $\begin{array}{l}1 \\
0 \\
0 \\
0 \\
0\end{array}$ \\
\hline Total .. & . & . & 100 & 36 & 29 & 18 & 2 & 13 & 1 & 1 \\
\hline
\end{tabular}

As a preliminary, it seemed important to know how often the resting cardiogram was normal in cases of unequivocal angina pectoris. Accordingly, a consecutive series of 100 patients, seen privately by one of us (P. W.), was analysed. The results are shown in Table I, and are in harmony with common experience. There were 44 with pure angina pectoris (with or without mild hypertension), 21 with serious hypertension (diastolic blood pressure $110 \mathrm{~mm}$. $\mathrm{Hg}$. or above), 18 with a history suggesting previous cardiac infarction, 14 with frequent and often prolonged attacks of pain at rest (acute or subacute coronary insufficiency), and 3 with aortic stenosis: no cases of syphilitic aortitis or severe anæmia happened to be encountered in this series. Of the total, 36 per 
cent had a normal resting cardiogram in standard, unipolar limb, and six chest leads (V1-V6); 29 per cent showed ischæmic depression of the RS-T segment in left ventricular surface leads or their equivalents (usually V4-6, VL, and standard lead 1); 20 per cent showed classical signs of cardiac infarction, mostly old; the remainder showed left ventricular preponderance with secondary T-wave changes (13), or bundle branch block (2). As would be expected; each clinical group tended to be characterized by its own electrocardiographic pattern. Thus, 70 per cent of those with uncomplicated angina pectoris had a normal resting curve; 54 per cent of those with serious hypertension or aortic stenosis showed the well known curve associated with left ventricular enlargement; 78 per cent of those with a history suggesting previous cardiac infarction gave cardiographic proof of it; and all those with acute coronary insufficiency showed ischæmic depression of the RS-T segment at rest.

The point emerges that approximately one-third of cases presenting with angina pectoris, and about two-thirds of those with uncomplicated angina of effort, have a normal electrocardiogram at rest. It is with this group only that we are further concerned.

Material. There were 100 patients with classical angina pectoris; they were selected solely because their resting cardiograms were strictly normal, provided they were not excluded by some other incapacitating disorder. There were 82 men and 18 women.

There were 100 controls with no evidence of cardiovascular disease; 73 were men and 27 women.

The ages of both patients and controls are presented in Table II. The controls averaged a decade younger, but over two-thirds of them were between 40 and 70 .

TABLE II

Ages of Patients and Controls

\begin{tabular}{lll|c|c|c|c|c|c|c}
\hline & - & $20-29$ & $30-39$ & $40-49$ & $50-59$ & $60-69$ & $\begin{array}{c}70 \text { and } \\
\text { over }\end{array}$ & Total \\
\hline Cases with angina &.. & - & 2 & 33 & 35 & 24 & 5 & 100 \\
Controls .. &.. &.. & 3 & 25 & 30 & 26 & 16 & - & 100 \\
\hline
\end{tabular}

Technique. The test evolved was simple and in principle consisted of continuous effort until the patient was pulled up by pain, dyspnœa, or fatigue. In private practice the maximum effort was limited by the top landing of the building in which the test was carried out, but there were 84 good steps from the consulting room to the top landing, and the patient was encouraged to climb them rapidly, at a moderate speed or slowly, according to the ease with which angina was said to be provoked by effort. As soon as the patient reached the top, or before if he became distressed on the way, he was hurried down again and immediately reconnected to the electrocardiograph. At hospital, the test was similar, but consisted of climbing up and down a twelve-inch step. The control cardiogram consisted of standard leads, unipolar limb leads, and six chest leads (V1-V6), and was recorded by means of a direct writing instrument. Sometimes CR leads were recorded instead of V leads. The electrodes were left in position during the effort test. Subsequent tracings were taken at half-minute intervals until the ventricular complexes resumed their normal rate and contour. Maximum changes were not necessarily immediate; indeed, true inversion of the $T$ wave, when it occurred, usually developed late during the recovery phase. The direct writing instrument enabled us to find the lead showing the most significant changes at once, and to check this from time to time without difficulty; it was usually lead V5. Again, when a diagnostic ischæmic pattern developed, it could be recognized immediately and all twelve leads could then be recorded.

The only patients with normal resting electrocardiograms who were not exercised were those who were prevented by other incapacitating conditions, such as osteoarthritis, intermittent claudi- 
cation, gross obesity, and senility. Controls were always exercised as fast as possible: on the top landing after 84 steps they were invariably breathless and fatigued; or they were pulled up by similar symptoms after climbing the twelve-inch platform 80-100 times.

\section{Results}

The majority of the controls showed little change except tachycardia (Fig. 1). Depression of the RS-T junction, however, was not uncommon and often measured 1-2 mm., but the RS-T segment then sloped rapidly upwards to a normal $\mathrm{T}$ peak (Fig. 2). In six instances slight flat

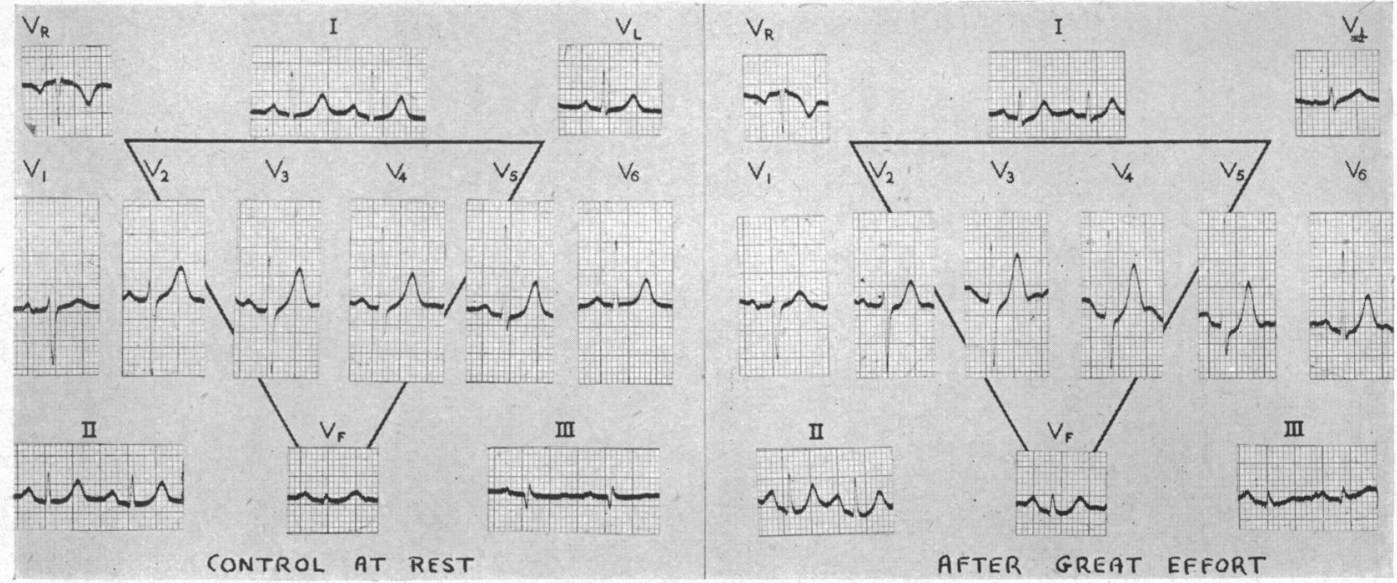

A

B

FIG. 1.-Normal control before and after effort, showing no significant change.

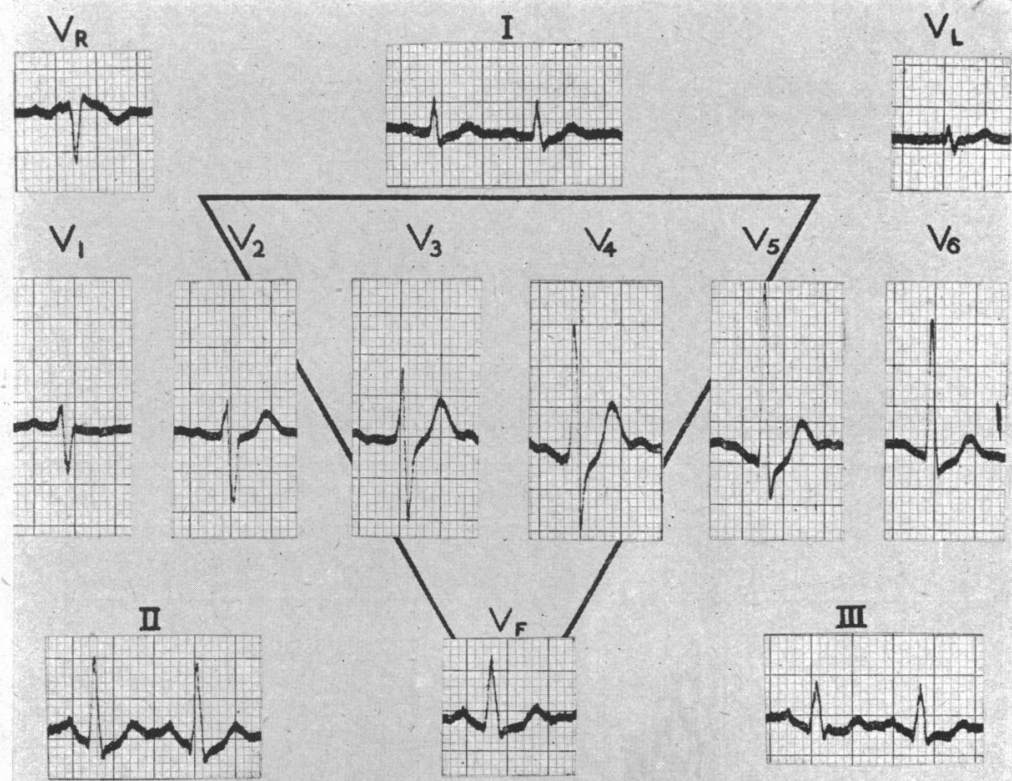

AFTER HURRYING UP 84 STEPS.

FIG. 2.-Normal control, showing depression of the S-T junction from which the S-T segment slopes rapidly upwards to a normal $\mathrm{T}$ peak. 


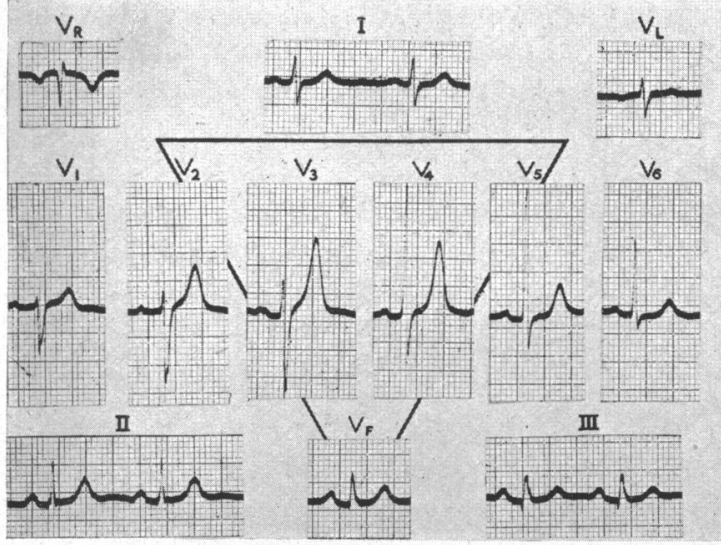

A

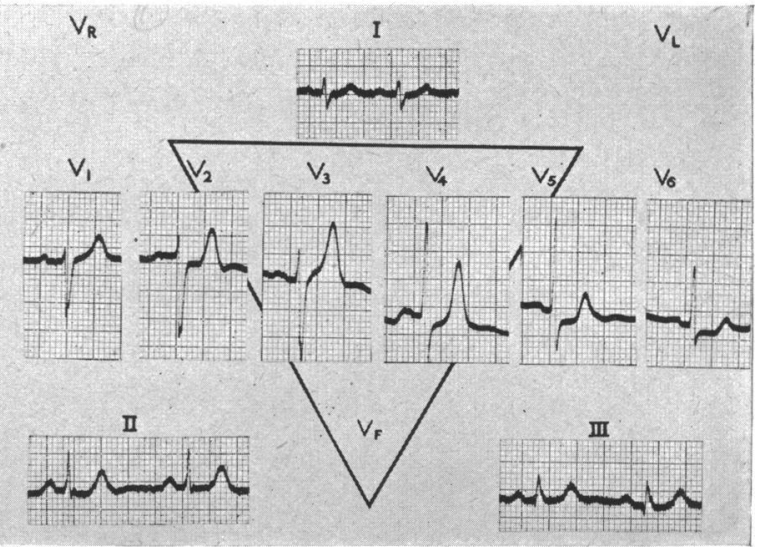

B

FIG. 3.-Case of angina pectoris showing flat depression of the S-T segment after effort, in leads V5 and V6.

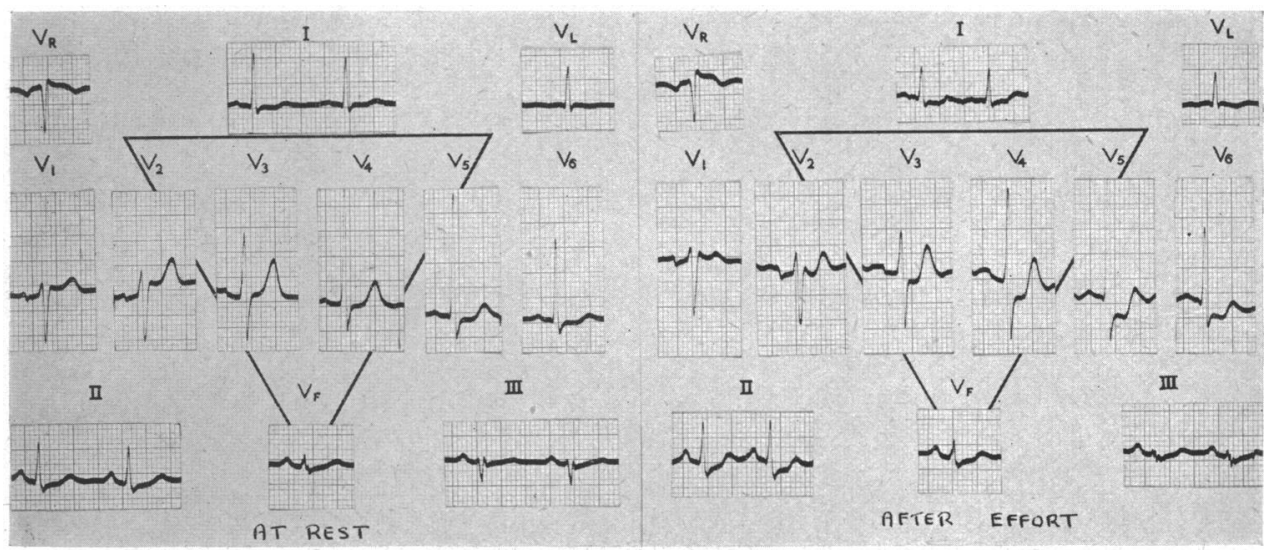

A

B

FIG. 4.-Case of angina pectoris showing sagging depression of the S-T segment after effort. No pain was felt during or after the test.

TABLE III

Analysis of Maximum Electrocardiographic Changes after Effort in 100 Cases of Angina Pectoris

\begin{tabular}{|c|c|c|c|c|c|c|c|c|}
\hline & \multicolumn{8}{|c|}{ Mm. below the $\mathrm{P}-\mathrm{Q}$ level (usually in lead V5) } \\
\hline & $1 \cdot 0$ & 1.5 & $2 \cdot 0$ & $2 \cdot 5$ & $3 \cdot 0$ & $3 \cdot 5$ & $4 \cdot 0$ & Total \\
\hline $\begin{array}{l}\text { Flat depression of the RS-T segment } \\
\text { (including } 4 \text { with completely flat T } \\
\text { waves) }\end{array}$ & 14 & 11 & 11 & 4 & 5 & 0 & 1 & 46 \\
\hline $\begin{array}{l}\text { Sagging of the RS-T segment (including } \\
\text { a few with diphasic T waves and } 2 \\
\text { with transient B.B.Bl.) }\end{array}$ & & & & & & & & \\
\hline $\begin{array}{ll}\text { with transient B.B.BI.) } & . .\end{array}$ & $\underline{3}$ & 11 & $\underline{9}$ & $\underline{2}$ & $\underline{4}$ & 1 & $\underline{6}$ & $\begin{array}{r}36 \\
6\end{array}$ \\
\hline No significant change..$\quad \ldots$ & - & - & 一 & - & - & 二 & 二 & 12 \\
\hline 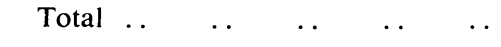 & - & - & 一 & - & - & - & - & 100 \\
\hline
\end{tabular}


depression of the RS-T segment was observed, but did not exceed $0.5 \mathrm{~mm}$. below the P-Q level. One control had a typical ischæmic curve and in two others depression was borderline.

The most reliable lead was V5. Conspicuous auricular T waves causing spurious depression of the RS-T segment were most frequent in standard lead II, but uncommon in left ventricular surface leads.

Of those with angina pectoris, 88 per cent developed characteristic ischæmic changes in left ventricular surface leads or their equivalents (Table III): these consisted of a current of injury causing horizontal depression (Fig. 3) or sagging (Fig. 4) of the RS-T segment of 1 to $4 \mathrm{~mm}$., a completely flat $\mathrm{T}$ wave, a diphasic $\mathrm{T}$ wave the first part of which was negative (Fig. 5), or actual inversion of the $\mathrm{T}$ wave (Fig. 6). Flat or sagging depression of the RS-T segment was by far the commonest change. Transient bundle branch block occurred in two, and extrasystoles in three cases. Inversion of the $\mathrm{U}$ wave (Palmer, 1948) developed in five cases, but was never the sole abnormality.

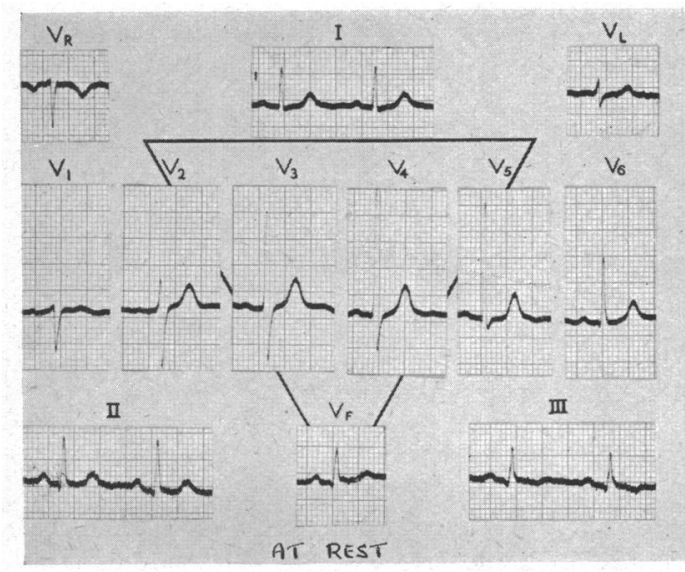

A
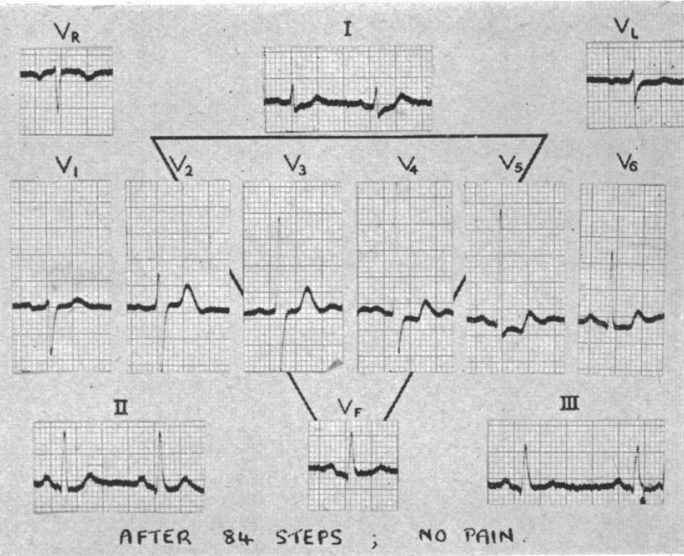

B

Fig. 5.-Case of angina pectoris showing a diphasic $\mathrm{T}$ wave in lead V5 after effort.

Angina pectoris was not produced by the work performed in as many as 30 cases; this was unexpected in view of the strenuous nature of the test. Despite the absence of pain, 26 of these 30 developed typical ischæmic tracings. In fact the incidence of positive tests was similar whether pain was present, slight, or absent (Table IV).

TABLE IV

Relationship of Positive Tests to Pain

\begin{tabular}{llll|c|c}
\hline & & & & No. of cases & Test positive \\
\hline Pain typical &.. &. &. & 58 & 51 or $88 \%$ \\
Slight pain.. &.. &. &. & 12 & 11 or $91 \%$ \\
No pain.. &. &.. &.. & 30 & 26 or $87 \%$ \\
\hline
\end{tabular}


Apart from inducing an attack of angina pectoris, to which the patient was accustomed, the test had no ill effect-not only in the present series, but also in a number of others who were rejected because their resting curves already showed slight ischæmic changes.

\section{Discussion}

Positive Results. The quality of the electrocardiographic changes that result from the effort test in cases of angina pectoris do not differ in any way from those previously described in spontaneous attacks (Bousfield, 1918; Feil and Siegel, 1928; Parkinson and Bedford, 1931), or in attacks deliberately provoked (Wood et al., 1931). We are concerned only with the value of the test in diagnosis.

The conclusions of previous workers in this respect have differed so widely from one another and from us that some explanation is needed. For instance, Levan (1945) obtained positive curves in 78 per cent of 37 cases of angina, accepting $0.75 \mathrm{~mm}$. depression of the RS-T segment in any lead as evidence of myocardial ischæmia. Unterman and de Graff (1948), demanding $1 \mathrm{~mm}$. depression of the S-T segment in any lead, and Grossman et al. (1949), accepting $0.75 \mathrm{~mm}$. depression in any limb lead and $1.5 \mathrm{~mm}$. in any chest lead, obtained positive results in about half their anginal subjects. Evans and Bourne (1941) exercised their patients along a corridor, which included a short flight of stairs, and obtained depression of the S-T segment from 0.5 to $2 \mathrm{~mm}$., diphasic $T$ waves or inverted $T$ waves in 8 out of 18 cases. Master et al. (1942), requiring more than $0.75 \mathrm{~mm}$. S-T depression in any lead, recorded positive tests after standard effort in 39 per cent of cases. Riseman et al. (1940) and Sigler (1940) concluded that the test was of no diagnostic value.

The criteria upon which a positive result has been based have also varied considerably. Most authors have agreed to accept flat $T$ waves in left ventricular surface leads or their equivalents, and all have accepted diphasic or inverted $T$ waves; but very few have agreed about the amount of depression of the S-T segment that distinguishes myocardial ischæmia from the normal. Some, e.g. Scherf (1947), demand as much as $1.5 \mathrm{~mm}$. in any lead; others, as mentioned above, only $0.75 \mathrm{~mm}$. Twiss and Sokolow (1942) require $1.0 \mathrm{~mm}$. in lead I, $1.5 \mathrm{~mm}$. in leads II or III, or $2 \mathrm{~mm}$. in lead IV; Mazer and Reisinger (1944) $0.75 \mathrm{~mm}$. in leads I or III, $1.5 \mathrm{~mm}$. in lead II, or $1.75 \mathrm{~mm}$. in lead CF4. Biorck (1946) demands a total depression of at least $2 \mathrm{~mm}$. when the limb leads are summated.

The chief criticism of much of such published work is that effort has been too often standardized (e.g. Master et al., 1942), and that the difference between depression of the RS-T junction and flat or sagging depression of the RS-T segment has not been appreciated. It cannot be right to fix the amount of work to be performed, when patients with angina vary from almost complete incapacity to a relatively high degree of effort tolerance. The maximum effort of which the individual is capable is the amount he should be encouraged to perform; in practice he is advised to stop if he develops pain, and is allowed to stop if 'obviously dyspnœic or exhausted.

Depression of the RS-T junction is normal after effort if the RS-T segment then slopes rapidly upwards to an upright $T$ peak, and there is no object in trying to distinguish between the normal and the ischæmic in this respect by setting a limit to the amount of depression. The depressed RS-T segment that denotes myocardial ischæmia is different in quality, being more or less flat or sagging: flat depression is unusual in controls, and rarely exceeds $0.25 \mathrm{~mm}$., whilst sagging depression is never seen. To guard against extreme normal variation we set the minimum ischæmic depression of the RS-T segment at $1 \mathrm{~mm}$.; even so, the majority of positive curves are far more depressed than this. Nor do we stipulate the lead in which such depression is found, although we advise recording lead V5 as soon as possible; standard lead II is the least reliable in view of the frequency of strong auricular $\mathrm{T}$ waves in this lead. Completely flat, biphasic, or inverted $\mathrm{T}$ waves in left ventricular surface leads or their equivalents do not occur at all in controls. 
The high proportion of positive results in our anginal series is particularly significant because of the care taken to exclude all cases showing slight ischæmic depression of the RS-T segment at rest. Such cases invariably developed gross changes on effort (Fig. 7). Finally, there can be no doubt that a reliable direct-writing electrocardiograph is very helpful in selecting the most informative leads, and that frequent records should be taken until the cardiogram has resumed its normal pattern.

Pain. We were surprised that a positive result was obtained as frequently in those who did not develop pain during the test as in those who did. This fact is not adequately explained by current theories concerning the mechanism of angina pectoris, nor is the repeated observation that "ischæmic" depression of the RS-T segment is usually exaggerated when the patient inhales amyl nitrite (Fig. 8), despite subsidence of pain when previously present. Of more practical importance, perhaps, is the obvious inference that it may be possible to detect latent angina pectoris by means of the effort test before attacks occur spontaneously. However, we have only twice succeeded in doing this, and there is no proof yet that we were.right.

Amongst our 100 controls were 33 cases of innocent left inframammary pain. Three of these developed pain during the effort test-of course with a normal electrocardiogram. The mere fact that pain does or does not occur during the test is therefore not good evidence in favour of or against angina pectoris.
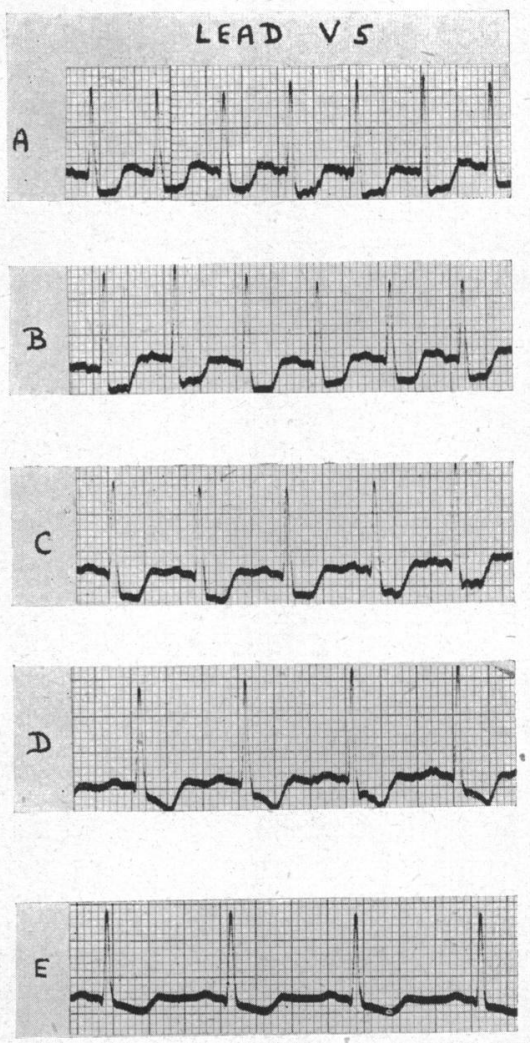

Fig. 6.-Case of angina 'pectoris, showing a series of electrocardiographic changes in lead V5 after effort. (A) and (B) Flat depression of the $R-T$ segment. (C) and (E) Sagging depression. (D) Inversion of the $\mathrm{T}$ wave.

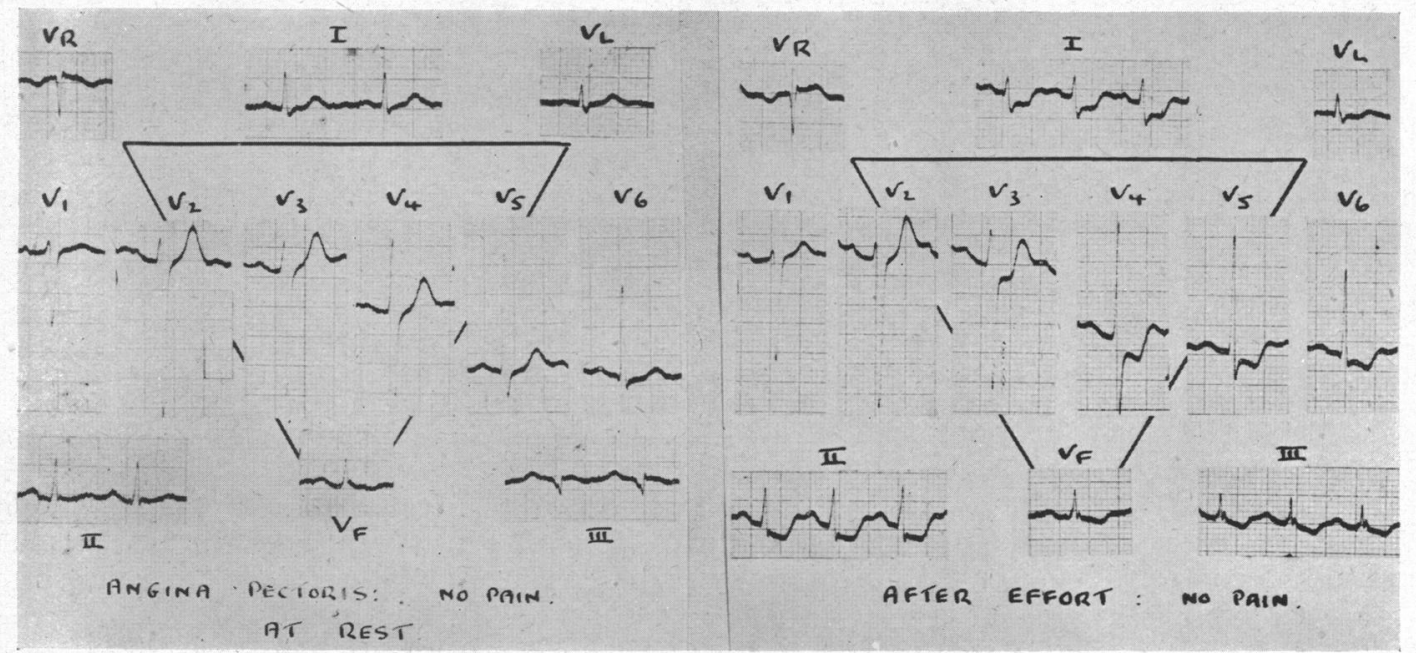

A

B

Fig. 7.-Electrocardiogram in a case of angina pectoris, showing minimal ischæmic depression of the S-T segment in lead V5 at rest, and gross changes after effort. 


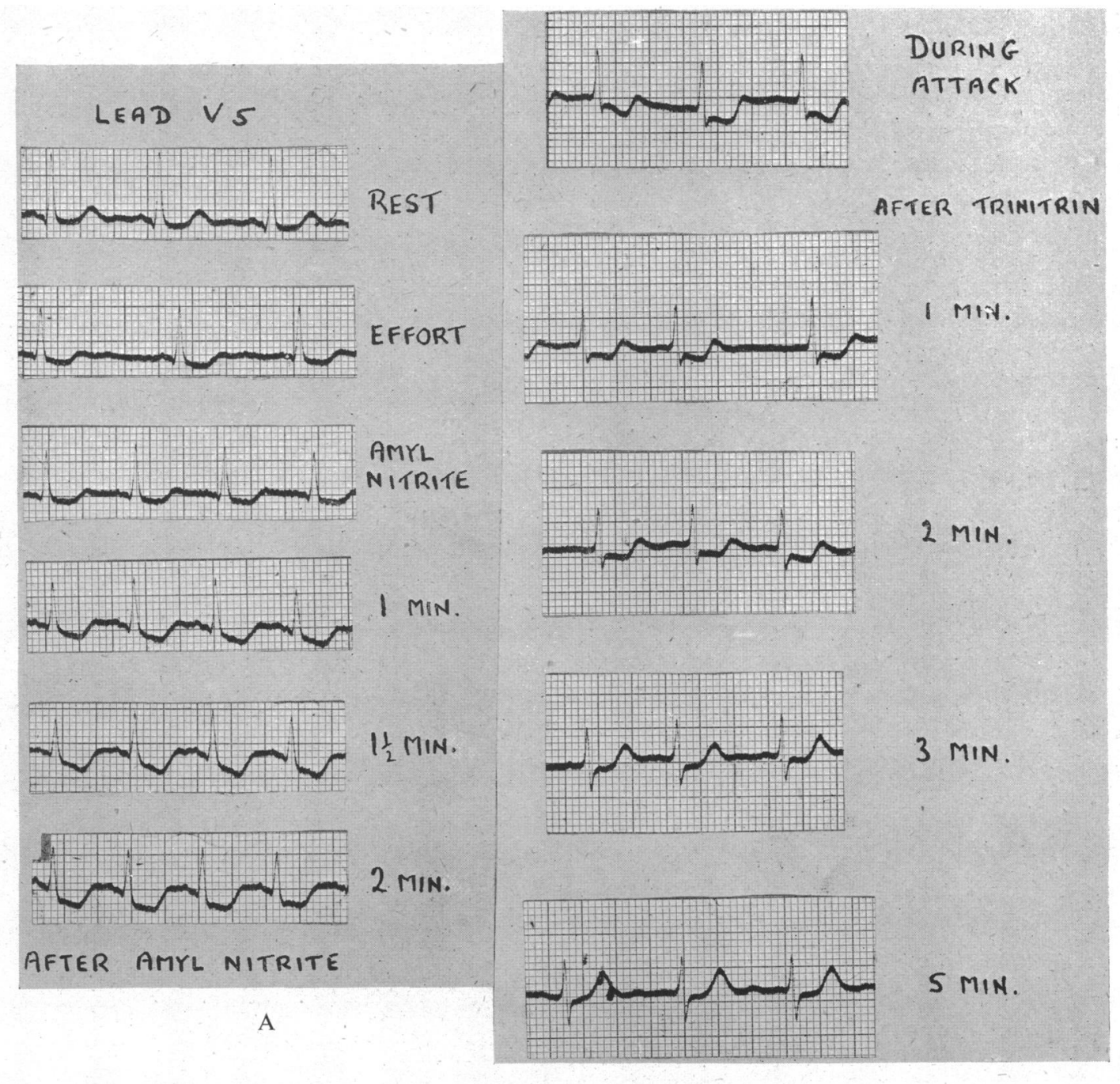

B

FIG. 8.-Comparative effects of amyl nitrite (A) and trinitrin (B) on ischæmic depression of the RS-T segment in two cases of angina pectoris. Both series of records are of lead V5.

\section{SUMmaRY AND CONCLUSIONS}

A series of 100 cases of unequivocal angina pectoris, selected solely because their electrocardiograms were normal at rest, and 100 normal controls were subjected to an effort test.

The test consisted in principle of the maximum effort of which the subject was capable, but for practical reasons a ceiling was sometimes imposed. Anginal subjects rarely performed as much work as the controls, being pulled up earlier by pain, dyspnoa, or fatigue; nor were they often encouraged to climb as rapidly.

Standard, unipolar limb, and multiple $\mathrm{V}$ chest leads were recorded before the test and immediately afterwards; the most revealing lead was then recorded at approximately half-minute intervals until the normal contour was resumed. 
A direct writing electrocardiograph was used. This enabled the best lead to be selected without difficulty, and facilitated frequent and rapid checking of this vital point.

Normal controls usually showed no change or depression of the RS-T junction, from which the RS-T segment sloped rapidly upwards to an upright $\mathrm{T}$ peak. Flat depression of the RS-T segment was sometimes seen during the recovery phase, but measured as much as $0.5 \mathrm{~mm}$. in only six cases. One subject exhibited an obvious ischæmic curve and could no longer be regarded as normal. Two others were doubtful.

Of the 100 patients with angina, 88 per cent developed changes that were not seen in controls. These consisted of flat or sagging depression of the RS-T segment from 1 to $4 \mathrm{~mm}$. below the P-Q level, or of a completely flat, diphasic, or inverted $\mathrm{T}$ wave in left ventricular surface leads or their equivalents.

When the heart rate after effort was at least 90 beats a minute, 95 per cent of 88 patients with angina developed diagnostic electrocardiographic changes; when the rate was less than 90 , the test was positive in only five out of twelve patients. The importance of sufficient effort is therefore emphasized.

Pain did not occur in approximately one-third of those who developed ischæmic curves; again, the incidence of positive tests was similar whether pain was typical, slight, or absent. The inference that latent angina pectoris may be recognized by the effort test is obvious.

\section{REFERENCES}

Biorck, G. (1946). Amer. Heart J., 32, 689, and Brit. Heart J., 8, 17.

Bousfield, G. (1918). Lancet, 11, 457.

Evans, C., and Bourne, G. (1941). Brit. Heart J., 3, 69.

Feil, H., and Siegel, M. L. (1928). Amer. J. med. Sc., 175, 255.

Grossman, M., Weinstein, W. W., and Katz, L. N. (1949). Ann. intern. Med., 30, 387.

Levan, J. B. (1945). War Med., 7, 353.

Levy, R. L., Patterson, J. E., Clerk, T. W., and Bruenn, H. G. (1941). Amer. med. Ass., 117, 2113, and Amer. Heart J., 21, 634.

Master, A. M., Friedman, R., and Dalk, S. (1942). Ibid., 24, 1942.

Mazer, M., and Reisinger, J. A. (1944). Ann. intern. Med., 21, 645.

Palmer, J. H. (1948). Brit. Heart J., 10, 247.

Parkinson, J., and Bedford, D.E. (1931). Lancet, 1, 15.

Riseman, J. E. F., Walker, J. V., and Brown, M. C. (1940). Amer. Heart J., 19, 683.

Scherf, D. (1947). New York State J. Med., 47, 2420.

Sigler, L. H. (1940). J. Lab. Clin. Med., 25, 796.

Twiss, A., and Sokolow, M. (1924). Amer. Heart J., 23, 498.

Unterman, D., and de Graff, A. C. (1948). Amer. J. med. Sci., 215, 671.

Wood, F. C., Wolferth, C. C., and Livsey, M. M. (1931). Arch. intern. Med., 47, 339. 